\title{
AVALIAÇÃO TÉCNICA E ECONÔMICA DE UM "FELLER-BUNCHER” OPERANDO EM DIFERENTES PRODUTIVIDADES
}

\author{
Haroldo Carlos Fernandes ${ }^{1}$, Sebastião Eudes Lopes ${ }^{2}$, Mauri Martins Teixeira ${ }^{3}$, Paula Cristina Natalino Rinaldi ${ }^{4}$,
} Paula Santana Fernandes ${ }^{5}$

\begin{abstract}
RESUMO
Este trabalho foi conduzido em povoamentos de eucalipto de uma empresa florestal do Estado de Goiás, com o objetivo de avaliar técnica e economicamente o trabalho de um "Feller-Buncher". A análise técnica consistiu do estudo de tempos e movimentos, além da produtividade, da disponibilidade mecânica e da eficiência operacional da máquina. A análise econômica consistiu na determinação dos custos operacionais e de produção. Foi empregado um delineamento estatístico inteiramente casualizado com 6 repetições em esquema de parcelas subdivididas. Adotou-se, como parcelas, as operações que compõe o ciclo operacional da máquina e como subparcelas os níveis de produtividade 100,200 e $300 \mathrm{~m}^{3} \mathrm{ha}^{-1}$. O "Feller Buncher" apresentou um custo de produção de 4,85; 2,83 e 1,64 US\$ $\mathrm{m}^{-3}$ para as produtividades de 100, 200 e 300 $\mathrm{m}^{3} \mathrm{ha}^{-1}$ respectivamente. $\mathrm{O}$ menor rendimento energético foi obtido para a maior produtividade do talhão.
\end{abstract}

Palavras-chave: máquinas florestais, produtividade, composição de custos.

\section{ABSTRAT \\ TECHNICAL AND ECONOMICAL EVALUATION OF A "FELLER-BUNCHER" UNDER DIFFERENT YIELD OPERATION}

The technical and economical performance of a "Feller-Buncher" was evaluated in a eucalyptus plantation of a forest company in the State of Goiás. The technical analysis was based on operating cycle of each machine through determination of periods and movements, yield, mechanical availability and operational efficacy. The economic analysis was based on operational and production costs. The data were evaluated with the use of a completely randomized design, with six replications, in a split-plot arrangement, with the machine operating cycle in whole plots and the yield levels in subplots. "Feller-Buncher" had a production cost of US\$ 4.85; 2.83, or $1.64 \mathrm{~m}^{-3}$, for a yield of 100,200 or $300 \mathrm{~m}^{3} \mathrm{ha}^{-1}$, respectively. The lowest energy use occurred in case of highest productivity.

Keywords: forest machines, productivity, composition of costs.

\section{Recebido para publicação em 09/10/2007. Aprovado em 25/03/2010.}

1-Engenheiro Agrícola, Professor Associado do Departamento de Engenharia Agrícola da Universidade Federal de Viçosa-MG, e-mail: haroldo@ufv.br 2- Engenheiro Mecânico, DS em Engenharia Agrícola - Mecanização Agrícola, UFV, Viçosa - MG, e-mail: industria@jatiboca.com.br 3- Engenheiro Agrônomo, Professor Associado do Departamento de Engenharia Agrícola, Universidade Federal de Viçosa - MG, e-mail: mauri@ufv.br 4- Engenheira Agrícola, Mestranda em Engenharia Agrícola - Mecanização Agrícola, UFV, Viçosa - MG, e-mail: pcnrinaldi@yahoo.com.br

5- Graduanda em Administração, UFV, Viçosa - MG, e-mail: paulasantanaf@gmail.com.

\section{REVENG} $210-218 \mathrm{p}$. 


\section{INTRODUÇ̃̃O}

O aumento da demanda de madeira para atender à produção de celulose expôs a necessidade de um aumento no consumo de madeira de florestas plantadas, o que engajou as empresas florestais a investir e buscar conhecimento em tecnologia silvicultural e de colheita florestal (SIMÕES \& FENNER, 2010).

A avaliação dos sistemas de colheita de madeira, independente do grau de mecanização utilizado, é uma ferramenta fundamental para correções ou qualquer alteração do processo de produção, visando a racionalização e otimização dos recursos utilizados. Trata-se, ainda, de instrumento indispensável na comparação de diferentes métodos ou equipamentos.

No Brasil, embora a mão-de-obra não qualificada ainda seja mal remunerada, os custos com este fator de produção têm sido incrementados pela evolução dos custos sociais. Moreira (1992) cita que houve grande aumento nos custos sociais ,no período de 1970 a 1992. Segundo ele, este índice pode ser maior ou menor, de acordo com a política de cada empresa, porém este aumento foi determinante para viabilizar a mecanização das operações florestais, em função do maior rendimento operacional oferecido por esta.

Machado e Lopes (1990) classificam os custos em diretos, indiretos e casuais. Os custos diretos são os relacionados com a mão-de-obra, materiais e outras despesas que afetam diretamente o custo total. Indiretos seriam os custos tais como aluguel, seguros, impostos e depreciação. Já os custos casuais são aqueles esporádicos, tais como multas ou prêmios por atraso ou entrega antecipada, respectivamente. Porém, há outros métodos de cálculo que consideram os custos com seguro e depreciação como custos diretos (MACHADO, 1994).

Para Miyata (1980), o custo operacional dos equipamentos é a base de cálculo para as avaliações econômicas e estudos comparativos entre sistemas, através da variação das grandezas de seus parâmetros. Os seus componentes são valor de aquisição, vida útil, valor residual, taxa de remuneração, seguros, utilização anual, mão-de-obra, combustível e manutenção dos maquinários (pneus, esteiras, pecas, etc). Já Valverde (1995) utilizou esta metodologia acrescentando o custo de administração.

O sistema de mecanização exige uso de máquinas que apresentem custos compatíveis com mínimo impacto no meio ambiente e proporcione ao operador boas condições de trabalho (MINETTE, 1988).

Os sistemas de colheita de madeira mais comuns são sistemas de toras longas e de toras curtas. O sistema de toras longas envolve o corte e o desgalhamento das árvores no local de abate, transporte dos mesmos e posteriores processamentos à margem da estrada ou no pátio.

Neste sistema, utilizam-se um conjunto mecanizado composto por "Feller-Buncher" e "Skidder". O "Feller-Buncher" é um trator florestal que realiza o corte e o agrupamento das árvores em feixes, preparando-as para os tratores "Skidders" efetuarem o deslocamento dos feixes até as margens da estrada ou pátio temporário.

Lima e Sant'ana (2001), trabalhando com "Feller-Buncher", verificaram que o tempo efetivo de trabalho da máquina não chegou a $30 \%$ do seu dia típico de trabalho, sendo que $48 \%$ do seu tempo foi gasto com as atividades gerais. Dentro das atividades gerais a manutenção corretiva foi a que consumiu o maior tempo, chegando a $34 \%$ do dia.

A análise das operações florestais estão geralmente, vinculada aos dados coletados. Freqüentemente, estes dados estão contidos em relatórios de estudos de tempo. Antes da coleta dos dados, as operações devem ser explicitamente definidas e separadas em nível de elemento (VALVERDE, 1995).

Em função disso, este trabalho tem por objetivo fazer uma análise técnica e econômica do trabalho do "Feller-Buncher" operando em diferentes produtividades.

\section{MATERIAL E MÉTODOS}

\section{Caracterização da área de estudo}

O trabalho foi conduzido em povoamentos florestais de uma empresa mineradora do grupo Anglo-America na região de Niquelândia no Estado de Goiás. O município está situado a $14^{\circ}$ $28^{\prime} 26^{\prime \prime}$ de latitude sul e $48^{\circ} 27^{\prime} 35^{\prime}$ "de longitude 
oeste, com $583 \mathrm{~m}$ de altitude, com clima tropical úmido, sendo a temperatura média do município em torno de $32^{\circ} \mathrm{C}$. O tipo de solo predominante na região é o Latossolo Vermelho-Escuro (LE), álico, Horizonte A moderado, com textura de média a arenosa e relevo plano a suave ondulado.

O sistema de colheita mecanizada utilizado na empresa é o de toras longas, que envolve o corte e desgalhamento das árvores no local de abate, transporte das mesmas e posterior processamento à margem da estrada ou no pátio.

Neste trabalho, foi avaliado o sistema de colheita efetuado por um "Feller-Buncher" da marca Caterpillar, modelo $320 \mathrm{C}$ com $103 \mathrm{~kW}$ de potência nominal (Figura 1), operando em três níveis de produtividade $\left(100,200\right.$ e $\left.300 \mathrm{~m}^{3} \mathrm{ha}^{-1}\right)$, considerado de baixa, média e alta produtividade, respectivamente.

Dentro do talhão selecionado, foram alocadas 6 parcelas com 4 repetições de 32 linhas de plantio cada. Procurou-se alocar as parcelas de forma que, dentro de cada uma, as condições de sub-bosque, terreno, declividade, padrão da floresta, entre outros, fossem as mais homogêneas possíveis, tentando eliminar as possíveis diferenças que não as atribuídas aos tratamentos.

\section{Descrição do sistema de corte, extração e traçamento.}

O sistema de colheita utilizado é de toras longas, em que as árvores são abatidas dentro do talhão e extraídas até a margem da estrada. A faixa de corte do "Feller-Buncher" adotada era de quatro linhas, em que a máquina trafega sobre a $2^{\mathrm{a}}$ linha de plantio, realizando o corte da $1^{\mathrm{a}}$ e $2^{\mathrm{a}}$ linhas por um lado e o da 3a e 4⿳亠丷厂 linhas por outro.

O "Feller-Buncher" iniciava a derrubada com quatro linhas de corte direcionando a base dos feixes das árvores para a extremidade do talhão. Cada talhão foi divido em 8 linhas de 100, 200 e 300 metros, de acordo com a distância preestabelecida para o posterior arraste. Após realizar a derrubada das quatro linhas, formando os feixes a aproximadamente $45^{\circ}$ em relação ao alinhamento de plantio, o "Feller-Buncher" retornava em direção ao início da segunda linha formando assim o talhão.

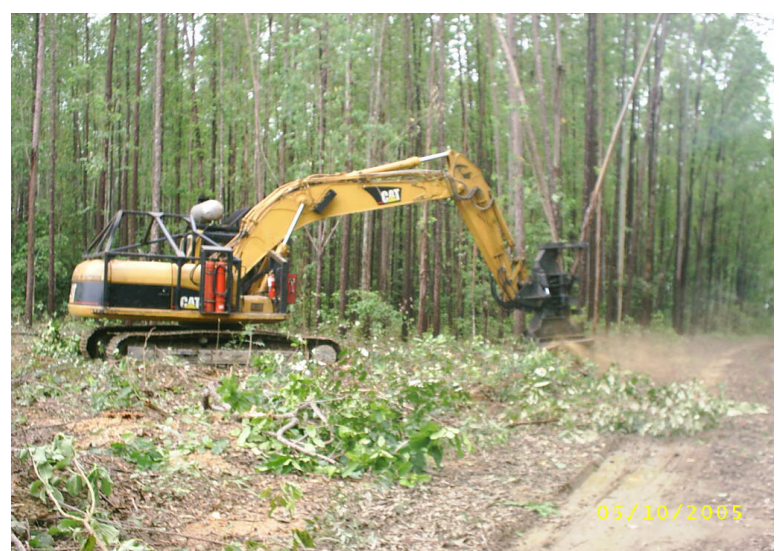

Figura 1. Vista geral do "Feller-Buncher".

\section{Ciclo operacional do Feller-Buncher}

Deslocamento vazio: iniciou-se exatamente quando, após completar a derrubada de um feixe, o "Feller-Buncher" dirigia-se ao encontro da próxima árvore (touça) que seria abatida e terminou quando apoiava o cabeçote de corte no chão, pronto para acionar o disco de corte.

Corte: iniciou-se quando o cabeçote de corte estava totalmente apoiado no chão, próxima à árvore que seria abatida, e terminou quando foi abatida a última árvore.

Deslocamento para o descarregamento: iniciouse quando os braços de corte estavam totalmente fechados e a última árvore estava cortada e terminou no instante em que todo o feixe estava no chão.

Interrupções: foram registrados todos os tempos em que a máquina não estava realizando as atividades anteriormente mencionadas, assim como uma descrição da causa de cada interrupção. Foram registradas as interrupções inerentes aos ciclos operacionais, também chamadas de dificuldades operacionais, vindo a fazer parte do tempo total do ciclo.

\section{Delineamento Estatístico}

Utilizou-se o delineamento estatístico inteiramente casualizado com 6 repetições em esquema de parcelas subdivididas. Adotou-se como parcelas as operações que compõem o ciclo operacional da máquina e como subparcelas os níveis de produtividade $\left(100,200\right.$ e $\left.300 \mathrm{~m}^{3} \mathrm{ha}^{-1}\right)$. Os valores foram submetidos à análise de variância e ao teste tukey a $5 \%$ de probabilidade.

\section{REVENG}




\section{Eficiência operacional}

Pode ser definido como percentagem do tempo efetivamente trabalhado, em relação ao tempo total programado para o trabalho. Pode ser expressa utilizando-se a equação 1 .

$$
f=\frac{t e}{(t e+t p)} \cdot 100
$$

em que

$f=$ eficiência operacional (\%);

$t e=$ tempo de trabalho efetivo (horas);

$t p=$ tempo de paradas (horas).

\section{Determinação da produtividade operacional}

Foi calculada por meio da equação 2 .

$$
\operatorname{Pr} o d=\frac{n a \cdot v a}{t e}
$$

em que

Prod $=$ produtividade operacional $\left(\mathrm{m}^{3} \mathrm{~h}^{-1}\right) ;$

$n a=$ número de árvores em cada parcela (un);

$v a=$ volume médio por árvore $\left(\mathrm{m}^{3}\right)$;

te $=$ tempo de trabalho efetivo (horas).

\section{Determinação dos custos operacionais}

Para determinar o custo operacional da máquina, utilizou-se o método descrito por Miyata (1980), acrescido do custo de administração, utilizado por Valverde (1995). O custo operacional foi analisado separadamente sendo dividido em custos fixos e variáveis, expressos em dólares por hora efetiva de trabalho (US\$ he-1).

\section{Custos fixos (CF):}

\section{Depreciação (Dp)}

Para o cálculo da depreciação, foi utilizado o método linear, de acordo com a equação 3.

$$
D p=\frac{V a-V p n-V r}{N \cdot h e}
$$

em que

$D p=$ depreciação linear da máquina (US\$ he $\left.\mathrm{e}^{-1}\right)$;

$V a=$ valor de aquisição da máquina (US\$);

$V r=$ valor residual da máquina (US\$);

$V p n=$ valor de um jogo de pneus (US\$);

$N=$ vida útil estimada (anos);

$h e=$ horas efetivas de uso anual.

\section{Juros sobre o capital (J)}

Os juros foram calculados utilizando-se a equação 4, sendo aplicado ao investimento médio anual (IMA) a uma taxa de juros correspondente ao custo de oportunidade em que seria aplicado o capital. Neste trabalho, utilizou-se uma taxa real de juros de $12 \%$ a.a:

$$
J=\frac{I M A \cdot i}{h e}
$$

em que

$J=$ juros (US $\$$ he $\left.^{-1}\right)$;

$i=$ taxa de juros(decimal);

$I M A=$ investimento médio anual (US\$), equação 5.

$$
I M A=\frac{(V a-V r) \cdot(N+1)}{2 \cdot N}+V r
$$

A taxa de seguros utilizada foi de $4 \%$ a.a, segundo os dados fornecidos pela empresa.

\section{Custos variáveis (CV):}

\section{Combustível (CC)}

A estimativa do custo de combustível foi baseada no consumo da máquina indicado pelo fabricante, sendo calculado utilizandose a equação 6 . 
$C C=P U . C$

em que

$C C=$ custo de combustível (óleo diesel) $\left(\mathrm{US} \$ \mathrm{he}^{-1}\right)$;

$P u=$ preço de um litro de óleo diesel (US\$ L ${ }^{-1}$ );

$C=$ consumo de óleo diesel por hora efetiva $\left(\mathrm{L} \mathrm{he}^{-1}\right)$.

\section{Custo de lubrificantes e graxas (CLG)}

Este custo foi considerado como um percentual dos custos com combustíveis, podendo ser calculado utilizando-se a equação 7 .

$$
C L G=1 L G . C C
$$

em que

$C L G=$ custo com lubrificantes e graxas (US\$ he $\left.{ }^{-1}\right)$; $I L G=$ índice de custos por máquinas com lubrificantes e graxas;

\section{Custo do óleo hidráulico (COH)}

Este custo foi considerado como um percentual dos custos com combustíveis, podendo ser calculado pela equação 8 .

$\mathrm{COH}=0,5 . \mathrm{C}$

em que

$C O H=$ custo com óleo hidráulico $\left(\mathrm{US} \$\right.$ he $\left.\mathrm{e}^{-1}\right)$;

\section{Custo de pneus/esteiras (CPE)}

Refere-se aos gastos com os rodados (pneus ou esteiras), podendo ser calculado utilizando-se a equação 9.

$C r=\frac{N r \cdot V r}{H r}$

em que
$\mathrm{Cr}=$ custo dos rodados $\left(\mathrm{US} \$ \mathrm{he}^{-1}\right)$;

$V r=$ valor de um pneu/esteira da máquina (US\$);

$\mathrm{Nr}=$ número de rodados (pneus/esteiras) por máquina;

$H r=$ vida útil do pneu/esteira, em horas efetivas.

Os custos relacionados com a manutenção, reparos mecânicos, transporte de pessoal e de maquinário, pessoal operacional e de administração foram fornecidos pela empresa em valores mensais e divididos pela quantidade de horas trabalhadas por mês.

\section{Custo operacional total (CT)}

Este custo foi obtido pela soma dos custos fixos, variáveis e os custos de administração de cada uma das máquinas analisadas neste trabalho, de acordo com a equação 10 .

$C T=C F+C V+C A$

em que

$C T=$ custo operacional total de cada máquina $\left(\mathrm{US} \$ \mathrm{he}^{-1}\right)$;

$C F=$ custos fixos $\left(\mathrm{US} \$ \mathrm{he}^{-1}\right)$;

$C V=$ custos variáveis $\left(\mathrm{US} \$ \mathrm{he}^{-1}\right)$;

$C A=$ custo de administração (US\$ he $\mathrm{e}^{-1}$ ).

\section{Determinação do custo de produção}

O custo de produção das máquinas foi obtido utilizando-se a equação 11 .

$C \operatorname{Pr}=\frac{C T}{\operatorname{Pr} o d}$

em que

$C \operatorname{Pr}=$ custo de produção da máquina analisada (US\$ $\mathrm{m}^{-3} \mathrm{cc}$ );

Prod $=$ produtividade da máquina analisada $\left(\mathrm{m}^{3} \mathrm{cc} \mathrm{he} \mathrm{e}^{-1}\right)$.

\section{Determinação do rendimento energético}

O rendimento energético das máquinas, equação 12, foi obtido pela razão entre o consumo específico de combustível e a produtividade de cada máquina, 
conforme as suas respectivas funções dentro de cada subsistema estudado.

$$
R E=\frac{C e}{\operatorname{Pr} o d}
$$

em que

$R E=$ rendimento energético da máquina analisada $\left(\mathrm{gkW}^{-1} \mathrm{~m}^{3} \mathrm{cc}\right)$;

$C e=$ consumo específico de combustível da máquina analisada $\left(\mathrm{gkW}^{-1} \mathrm{~h}^{-1}\right)$.

\section{RESULTADOS E DISCUSSÃO}

No Quadro 1 é apresentada a análise de variância para os valores de tempo gasto nas operações do ciclo operacional do "Feller Buncher" nas produtividades analisadas.

Os valores médios dos tempos gastos para realizar o ciclo operacional nos diferentes níveis de produtividades são mostrados no Quadro 2, juntamente com os testes de média.

Esses valores correspondem a um ciclo operacional de corte, composto de 4,22; 4,07 e 2,50 árvores abatidas, em média, por ciclo, nas produtividades de 100; 200 e $300 \mathrm{~m}^{3} \mathrm{ha}^{-1}$, respectivamente.

Os tempos gastos nas operações de corte, deslocamento vazio e interrupções em todas as produtividades foram as que demandaram os maiores tempos. Não houve diferença estatística nos tempos gastos para realizar essas operações nas produtividades de 100 e $200 \mathrm{~m}^{3} \mathrm{ha}^{-1}$. Já para a produtividade de $300 \mathrm{~m}^{3} \mathrm{ha}^{-1}$, a operação deslocamento para descarga registrou diferença dos demais tempos.

Moreira et al. (2004), trabalhando com o Fellerbuncherem dois subsistemas de colheita, concluíram que os elementos parciais que consumiram a maior parte do tempo do ciclo operacional foram o busca e o corte, com aproximadamente $50 \%$ do tempo total do ciclo nos dois subsistemas analisados, mostrando valores próximos em ambos; os elementos deslocamento vazio e descarregamento vieram em seguida, abrangendo, juntos, cerca de 37 a $39 \%$ do tempo total do ciclo do "Fellerbuncher".

Quadro 1. Análise de variância para os valores de tempo gasto nas operações do ciclo operacional do Feller Buncher nas produtividades analisadas

\begin{tabular}{lcccc}
\hline Fonte de Variação & G. L. & QM & F & $\alpha$ \\
\hline Operação & 3 & 3722,64 & 24,01 & 0,00 \\
Resíduo a & 20 & 155,05 & & \\
Produtividade & 2 & 3432,72 & 48,99 & 0,00 \\
Operação*Produtividade & 6 & 228,84 & 3,27 & 1,04 \\
Resíduo b & 40 & 70,06 & & \\
Total & 71 & & & \\
\hline
\end{tabular}

Coeficiente de Variação (Parcela) $=36,29 \%$

Coeficiente de Variação (Subparcela) $=24,39 \%$

Quadro 2. Tempos gasto (s) para realizar cada ciclo operacional nos diferentes níveis de produtividade

\begin{tabular}{lccc}
\hline \multirow{2}{*}{ Operações } & \multicolumn{3}{c}{ Produtividade $\left(\mathrm{m}^{3} \mathrm{ha}^{-1}\right)$} \\
\cline { 2 - 4 } & $54,59 \mathrm{Aa}$ & 490 & 300 \\
\hline Tempo Corte (Carga e Descarga) & $50,77 \mathrm{Aa}$ & $48,91 \mathrm{Aa}$ & $16,19 \mathrm{Ab}$ \\
Deslocamento Vazio & $17,39 \mathrm{Ba}$ & $13,67 \mathrm{Ba}$ & $8,73 \mathrm{Ba}$ \\
Deslocamento Para Descarga & $52,47 \mathrm{Aa}$ & $41,07 \mathrm{Aa}$ & $22,10 \mathrm{Ab}$ \\
Interrupções &
\end{tabular}

Médias seguidas pela mesma letra, minúscula na linha e maiúscula na coluna, não diferem entre si, pelo teste Tukey, a $5 \%$ de significância. 


\section{Análise dos elementos do ciclo operacional do Feller-Buncher}

\section{Deslocamento vazio}

Não houve diferença significativa entre as produtividades 100 e $200 \mathrm{~m}^{3} \mathrm{ha}^{-1}$ em relação ao tempo gasto para realizar esta operação. Notouse que, no talhão de produtividade igual a 100 e $200 \mathrm{~m}^{3} \mathrm{ha}^{-1}$, o operador procurava acumular o máximo de árvores possíveis no cabeçote de forma a tentar otimizar a etapa de extração feita com o Skidder. Para a produtividade de $300 \mathrm{~m}^{3}$ $\mathrm{ha}^{-1} \mathrm{o}$ maior número de árvores por hectare, fez com que o operador não perdesse tempo em descolar com o cabeçote em busca de novas árvores, ou seja, após o descarregamento, o percurso vazio até as próximas árvores a serem abatidas foi menor, gerando menor tempo de deslocamento sem carga.

\section{Corte}

Não houve diferença significativa de produtividades em relação ao tempo gasto para realizar esta operação nas produtividades de 100 e $200 \mathrm{~m}^{3} \mathrm{ha}^{-1}$.

\section{Deslocamento para o descarregamento}

Em todas as produtividades o tempo desta operação não apresentou diferença significativa.

\section{Interrupções}

As interrupções foram divididas em mecânicas e operacionais, vindo, portanto, a fazer parte do tempo total do ciclo.

O "Feller-Buncher" estudado utiliza em seu cabeçote, um disco de corte com 16 cortadores em forma de copo, pelo posicionamento dos cortadores no disco de corte, apenas uma parte da área do cortador entra em contato com a árvore durante a etapa de corte.

Depois um determinado número de horas em uso, os cortadores são virados em $90^{\circ}$, posicionando a parte ainda não utilizada para o contato com a árvore. Estas interrupções foram observadas com maior freqüência na produtividade de $300 \mathrm{~m}^{3} \mathrm{ha}^{-1}$ devido a maior incidência do rebaixamento de cepas.

As interrupções operacionais foram constituídas na sua totalidade pelo tempo parado para refeição e limpeza da cabine durante o período de coleta de dados, as quais foram pré-estabelecidas e portando não houve diferença dentre as produtividades analisadas.

Não houve diferença estatística significativa entre as produtividades de 100 e $200 \mathrm{~m}^{3} \mathrm{ha}^{-1}$ em relação às interrupções. A diferença foi significativa no talhão de $300 \mathrm{~m}^{3} \mathrm{ha}^{-1}$ onde observou que o operador não perdia tempo para eliminar sub-bosque, procurar árvores e arranjar feixes.

\section{Tempo efetivo total do ciclo operacional}

A análise dos tempos totais que compõe o ciclo operacional "Feller Buncher" e o teste de media estão apresentados nos Quadro 3 e 4.

Quadro 3. Análise estatística dos tempos totais que compõe o ciclo operacional

\begin{tabular}{lcccc}
\hline Fonte de Variação & G. L. & QM & F & $\alpha$ \\
\hline Produtividade & 2 & 13730,89 & 36,76 & 0,00 \\
Resíduo a & 15 & 373,45 & & \\
Total & 17 & & & \\
\hline
\end{tabular}

Coeficiente de Variação $=14.08 \%$

Quadro 4. Teste de média dos tempos totais (segundos) que compõe o ciclo operacional

\begin{tabular}{cccc}
\hline \multicolumn{4}{c}{ Produtividade $\left(\mathrm{m}^{3} \mathrm{ha}^{-1}\right)$} \\
\hline Tempo Total & 100 & 200 & 300 \\
\hline
\end{tabular}

Médias seguidas pela mesma letra, minúscula na linha e maiúscula na coluna, não diferem entre si, pelo teste Tukey, a $5 \%$ de significância. 
Quadro 5. Custo de produção e rendimento energético do "Feller-Buncher", em função do volume madeira produzido

\begin{tabular}{ccc}
\hline $\begin{array}{c}\text { Produtividade } \\
\left(\mathrm{m}^{3} \mathrm{he}^{-1}\right)\end{array}$ & $\begin{array}{c}\text { Custo produção } \\
\left(\mathrm{U} \$ \$ \mathrm{~m}^{3} \mathrm{cc}^{-1}\right)\end{array}$ & $\begin{array}{c}\text { Rendimento energético } \\
\left(\mathrm{g} \mathrm{kW} \mathrm{m}^{3} \mathrm{cc}^{-1}\right)\end{array}$ \\
\hline 100 & 4,97 & 13,75 \\
200 & 2,90 & 7,12 \\
300 & 1,68 & 4,65 \\
\hline
\end{tabular}

O "Feller Buncher" apresentou tempo médio total de 175,$23 ; 152,99$ e 83,52 segundos para cortar em média 4,22; 4,07 e 2,5 árvores nas produtividades de $100 ; 200$ e $300 \mathrm{~m}^{3} \mathrm{ha}^{-1}$. No quadro está mostrado a interferência do volume de madeira nos tempos gastos para realizar o ciclo operacional da máquina.

\section{Análise da produtividade}

A produtividade por hora efetiva do "Feller Buncher" foi de 13,81; 23,67 e 40,84 $\mathrm{m}^{3}$ quando trabalhou nos talhões de $100,200 \mathrm{e}$ $300 \mathrm{~m}^{3} \mathrm{ha}^{-1}$.

A produção da máquina tende a ser significativa para as produtividades analisadas, os volumes de madeira produzidos demonstram a influência deste no rendimento da máquina.

\section{Custo operacional, custo de produção e rendimento energético}

Considerando-se uma taxa de juros de $12 \%$ a.a. e uma eficiência mecânica de $85 \%$, chegou-se ao custo/hora efetivamente trabalhada de US\$ 68,62.

Os custos fixos corresponderam a aproximadamente, $21,49 \%$, e os custos variáveis, aproximadamente $74,68 \%$ dos custos totais, respectivamente. $\mathrm{O}$ custo de administração foi da ordem de 3,82\% dos custos totais.

Simões e Fenner (2010), avaliando o custo de uma máquina de colheita florestal, concluíram que a somatória dos custos fixos e variáveis apresentou um custo operacional médio de US\$ 78.78 por hora efetiva de trabalho.

O "Feller-Buncher" apresentou um custo de produção de US $\$ 4,97 ; 2,90 \mathrm{e} 1,68$ para a produtividade de 100,200 e $300 \mathrm{~m}^{3} \mathrm{ha}^{-1}$. Com o consumo específico de combustível de $190 \mathrm{~g} \mathrm{~kW} \mathrm{~h}^{-1}$, os rendimentos energéticos foram obtidos dividindo o consumo especifico pela produção, conforme apresentado no Quadro 5.

À medida que a produtividade aumentou, a produtividade da máquina também aumentou e os valores do custo de produção e do rendimento energético diminuíram, demonstrando que a produtividade do talhão influenciou diretamente no custo de produção do "Feller Buncher".

Os autores Valverde (1995) e Moreira (2000), obtiveram resultados semelhantes, indicando que as máquinas empregadas na operação de corte de madeira são sensíveis aos diferentes níveis de volume médio por árvore e seu rendimento em termos de volume por unidade de tempo, tende a crescer com o aumento do volume médio por árvore.

\section{AGRADECIMENTO}

Agradecemos a FAPEMIG, Fundação de Amparo a Pesquisa do Estado de Minas Gerais pelo apoio para a realização deste trabalho.

\section{CONCLUSÕES}

Nas condições em que o experimento foi conduzido, pode-se concluir que:

- O custo total por hora efetiva de trabalho é de US\$ 68,62;

- A produtividade da máquina é diretamente proporcional à produtividade do talhão;e

- Tanto o custo de produção quanto o rendimento energético diminuem com o aumento da produtividade do talhão. 


\section{REFERÊNCIAS BIBLIOGRÁFICAS}

LIMA, A.S.; SANTA'ANNA, C.M. Estudo de tempos e movimentos na colheita de eucaliptos em sistema de árvore inteira. In: $5^{\circ}$ Simpósio Brasileiro Sobre Colheita e Transporte Florestal. Porto Seguro, BA, 2001. Anais... Porto Seguro, 2001. p. 265-280.

MACHADO, C.C.; LOPES, E. S. Análise da influência do comprimento de toras de eucalipto na produtividade e custo da colheita e transporte florestal. Cerne, v.6, n.2, p.124 - 129, 1990

MACHADO, C.C. Planejamento e controle de custos na exploração florestal. Viçosa: UFV, Imprensa Universitária, 1994. 138p.

MINETTE, L.J. Avaliação técnica e econômica dos tratores florestais transportadores (Forwarders) na extração de madeira de eucalipto. Viçosa, 1988. 77p. Dissertação (Mestrado em Ciência Florestal) - Universidade Federal de Viçosa.
MIYATA, O. P. Custo operacional de máquinas utilizadas na exploração e transporte da cultura do eucalipto. Informe Agropecuário, n. 141, p. 24 30, 1980 .

MOREIRA, A.T. Análise técnica e operacional de colheitadeiras florestais. Rio de Janeiro: UFRRJ, 1992. p. $261-278$.

MOREIRA F. M. T. Análise técnica e econômica de subsistemas de colheita de madeira de eucalipto em terceira rotação. Viçosa, MG: UFV, 2000. 148 p. Dissertação (Mestrado em Ciência Florestal) - Universidade Federal de Viçosa, 2000.

SIMÕES, D.; FENNER, P.T. Influência do relevo na produtividade e custos do harvester. Scientia Forestalis, v. 38, n.85, p.107-114, 2010.

VALVERDE, S.R. Análise técnica e econômica do subsistema de colheita de árvores inteiras em povoamentos de eucalipto. Viçosa, MG: UFV, 1995. 123p. Dissertação (Mestrado em Ciência Florestal) - Universidade Federal de Viçosa, 1995. 